\title{
\begin{tabular}{l|l} 
8th International Conference on \\
Humanities, Psychology and Social Science \\
October 19-21,2018 Munich, Germany
\end{tabular}
}

\section{Nostalgia as a Coping Mechanism in NoViolet Bulawayo's We Need New Names}

\author{
Nihal Zaki \\ Faculty of A-Alsun (foreign languages), Minia University, Egypt
}

This paper explores how NoViolet Bulawayo's We Need New Names(2013) shows nostalgia as a mean of coping with acculturative stress. It draws on the studies of social and cross-cultural psychology as well as post-colonialism within the framework of migration, acculturation, acculturative stress and nostalgia to examine what happens to the protagonist who was raised in one cultural setting, namely Zimbabwe, when she tries to re-establish her life in another setting, namely U.S.A. In her efforts to integrate in the dominant society, Darling encounters Racism, economic problems and identity crisis. A subsequent psychological effect of these harsh conditions is acculturative stress, which bears negative consequences on the psychological wellbeing. By close reading of the novel, I argue, against the prevailing perception, that nostalgia constitutes a resource in coping with the acculturative stress of the protagonist by inspiring positive influence. Moreover, I observe that nostalgia not only help the protagonist in developing social awareness of the world, but also it contributes in developing her integrated identity that will assist her in the process of adaptation.

Keywords: Migration, Acculturation, Acculturative Stress, Nostalgia, Coping Mechanism, PostColonialism. 